\title{
Consumer behaviour in the waiting area
}

\author{
Mark P. Mobach
}

Received: 16 February 2005 / Accepted: 2 October 2005/Published online: 31 January 2007

(C) Springer Science+ Business Media B.V. 2007

\begin{abstract}
Objective of the study: To determine consumer behaviour in the pharmacy waiting area. Method: The applied methods for data-collection were direct observations. Three Dutch community pharmacies were selected for the study. The topics in the observation list were based on available services at each waiting area (brochures, books, illuminated new trailer, children's play area, etc.). Per patient each activity was registered, and at each pharmacy the behaviour was studied for 2 weeks. Results: Most patients only waited during the waiting time at the studied pharmacies. Few consumers obtained written information during their wait. Conclusion: The waiting area may have latent possibilities to expand the information function of the pharmacy and combine this with other activities that distract the consumer from the wait. Transdisciplinary research, combining knowledge from pharmacy practice research with consumer research, has been a useful approach to add information on queueing behaviour of consumers.
\end{abstract}

Keywords Community pharmacy .

Consumer behaviour · Information .

The Netherlands · Waiting area

\section{Introduction}

It is quite clear today that only dispensing of medicine is not enough for pharmacy services. The provision of oral and written information is an important property of pharmaceutical care in community-based pharmacy. Much of the available literature deals with individual consultation at pharmacies [1]. In terms of the pharmacy interior, this consultation can be expected at the counter and/or in a separate room. Although this

M. P. Mobach $(\bowtie)$

Faculty of Management and Organization,

P.O. Box 800, 9700 AV, Groningen, The Netherlands

E-mail: m.p.mobach@rug.nl probably covers the main part of the information provided, a small part of the information is also present in the pharmacy waiting area. But is this information really used by the patients? In order to address this question consumer behaviour was observed in the waiting area of community-based pharmacies in The Netherlands.

\section{Objective}

The objective of this paper is to determine consumer behaviour in the pharmacy waiting area.

\section{Theoretical perspective}

What consumers do during their stay in the pharmacy waiting area has not yet been addressed in pharmacy practice research. However, in consumer research we can find results that are useful in this context, although to a limited extent and in other sectors (e.g. supermarket, department store, and bank) [2]. In general, waiting for service is regarded as a typically negative consumer experience, which may cause impatience, frustration, and annoyance [3]. Research has shown that consumers generally overestimate the duration of their waiting time [2], resulting in a reduction of service evaluation [4, 5]. As a consequence, researchers have attempted to define strategies to reduce these negative effects of the perceived waiting time. Distraction during the waiting time seems to be the key concept. Pharmacists are advised to entertain, enlighten and engage the consumers during their wait [4]. It makes the wait more palatable and improves service evaluation [2, 4]. However, there is more to waiting than distraction. Following Bonnin [6] we may expect waiting areas to be functional, active ludic, or passive ludic. A functional space design aims at efficient behaviour, for instance, efficient routing, fast handling, and a clear and fair queueing system. This space serves 
consumers with a so-called epistemic search strategy (the runshopper): they come to the pharmacy for the sole purpose of locating and purchasing the desired medicine. An active ludic space design aims at shopping entertainment, for instance, an aquarium, a newspaper, a water tap, a coffee machine, and a children's play area. A passive ludic space design aims at micro-events where the curiosity of consumers should be moderate leading to superficial actions, for instance, the availability of brochures, Internet-connections, and possibilities to grasp and look at OTC-products. These latter two spaces serve consumers with a so-called hedonic search strategy (the funshopper): they use the visit to enhance the overall quality of the shopping experience and satisfy the pursuit of pleasure. Following the distinctions from above, the activities of consumers in the pharmacy waiting area were classified in pharmaceutical care related activities (distracting through informing) and other activities (distracting or being inactive). This classification was used to study what consumers do during their wait.

\section{Method}

This current research is transdisciplinary [7], as it uses the above theoretical framework from consumer research as a starting point for empirical research in pharmacy practice. By doing so, it not only passes the borders of pharmacy practice research, but also aims to come back with new knowledge. For that purpose, three Dutch community pharmacies were selected based on their motivation to participate in the study. The study was not designed for generalization purposes or for comparison between the cases: the sample size was not random, far too small and the waiting areas did have too many differences. It may be regarded as a study in the context of discovery. The applied method for data collection was direct observation. The topics in the observation list were based on available services at each waiting area. Consequently, there were differences in each of the lists due to different properties of each waiting area. The main consumer activities comprised conversing, drinking, looking, playing, reading, and waiting. All three lists comprised detailed topics such as: reading brochures, conversing with other consumers, and waiting only. Depending on the local situation other topics were added (see Table 1 for details). Per patient each activity was registered. At each pharmacy the behaviour was studied for 2 weeks during the spring of 2004.

\section{Results}

Table 1 shows that $12 \%$ (760) of the queued patients did perform pharmaceutical care related activities in the waiting area. A total of $88 \%$ (5813) of the patients performed other activities. In this latter group 77\% (5050) of the queued patients were inactive during their wait.

\section{Discussion}

From the perspective of the physical environment of the community-based pharmacy we can expect individual consultations at the counter and in a separate room. On one hand, it is evident that these spaces are the natural moment to provide information to the patient, which justifies a research focus on these spaces in other studies. Within this line of thought it will be better if other information is also available in the waiting area, but it is certainly not the core business of a pharmacy. The provision of information via the waiting area may indeed have limited impact. It is just a small part of the information provided by the

Table 1 Consumer behaviour in the waiting area

\begin{tabular}{|c|c|c|c|c|c|c|c|c|c|c|c|c|c|}
\hline \multirow{2}{*}{$\begin{array}{l}\text { Cases } \\
\text { Measures observed items }\end{array}$} & \multicolumn{4}{|c|}{ Pharmacy 1} & \multicolumn{4}{|c|}{ Pharmacy 2} & \multicolumn{4}{|c|}{ Pharmacy 3} & \multirow{2}{*}{$\begin{array}{l}\text { Total } \\
\Sigma\end{array}$} \\
\hline & $\Sigma$ & $\mu$ & $\%$ & $\sigma$ & $\Sigma$ & $\mu$ & $\%$ & $\sigma$ & $\Sigma$ & $\mu$ & $\%$ & $\sigma$ & \\
\hline Reading brochures & 153 & 14.4 & 6.3 & 6.1 & 65 & 6.5 & 3.6 & 4.1 & 107 & 10.7 & 4.6 & 5.4 & 325 \\
\hline Looking at/grasping OTC & & & & & 205 & 20.5 & 11.2 & 3.9 & 8 & 0.8 & 0.4 & 0.9 & 213 \\
\hline Reading newspaper of pharmacy formula & 57 & 5.4 & 2.4 & 3.6 & & & & & 99 & 9.9 & 4.3 & 5.3 & 156 \\
\hline Reading illuminated news trailer & 19 & 2.7 & 0.8 & 2.3 & 6 & 0.6 & 0.3 & 1.0 & & & & & 25 \\
\hline Reading books on illness and well-being & 22 & 2.1 & 0.9 & 2.5 & & & & & & & & & 22 \\
\hline Looking at display window & & & & & & & & & 19 & 1.9 & 0.8 & 3.0 & 19 \\
\hline Subtotal pharmaceutical care related activities & 251 & 24 & 10 & 7.1 & 276 & 27.6 & 15 & 6.8 & 233 & 23.3 & 10 & 7.3 & 760 \\
\hline Waiting only & 1878 & 177.2 & 77.3 & 24.7 & 1346 & 134.6 & 73.6 & 17.5 & 1826 & 182.6 & 78.9 & 12.5 & 5050 \\
\hline Conversing with other consumers & 251 & 23.7 & 10.3 & 9.3 & 152 & 15.2 & 8.3 & 6.8 & 84 & 8.4 & 3.6 & 4.4 & 487 \\
\hline Reading ordinary newspaper & & & & & & & & & 171 & 17.1 & 7.4 & 5.4 & 171 \\
\hline Using children's play area & 51 & 4.8 & 2.1 & 3.3 & 15 & 1.5 & 0.8 & 1.2 & & & & & 66 \\
\hline Drinking water & & & & & 39 & 3.9 & 2.1 & 2.3 & & & & & 39 \\
\hline Subtotal other activities & 2180 & 206 & 90 & 16.7 & 1552 & 155.2 & 85 & 19.0 & 2081 & 208.1 & 90 & 11.9 & 5813 \\
\hline Total activities & 2431 & 230 & 100 & 18.9 & 1828 & 182.8 & 100 & 20.2 & 2314 & 231.4 & 100 & 13.9 & 6573 \\
\hline
\end{tabular}


pharmacy. On the other hand, the waiting area may also be regarded as a wonderful opportunity to stimulate the patient's interest in the possibilities of medical treatment and combine this with distraction from the wait. From this point of view the waiting area may be regarded as a latent source of information and distraction for the patient. However, it seems that both possibilities have not yet been used to its full potential and have been subject to undeserved neglect in pharmacy practice research. In this paper the latter perspective is followed and it is connected with the possible intentions consumers may have.

From the fact that most consumers are inactive four assumptions about their intentions can be derived: (1) they like to be inactive, (2) they have to be inactive, (3) they have potential interest for serious information, and (4) they have potential interest for distraction.

Assumption 1 Consumers like to be inactive. The first explanation for the inactiveness of patients may be that the patients' thoughts are not occupied with any of the stimuli in the physical environment. Pharmacists will have to accept the fact that some patients are not interested in any of the materials displayed. Although these patients miss an opportunity to inform themselves in the waiting area, there is no harm in their behaviour.

Assumption 2 Consumers have to be inactive. Patients may have to guard their position in the queue, like in other shops, which hinders the gathering of information. This occupation finds its origin in two problems: sequence and timing. Sequence is about their exact position in the queue: who is ahead and who behind. Timing is about the exact moment they will have contact with the pharmacy staff.

Assumption 3 Consumers have potential interest for serious information. The results show that $12 \%$ of the patients have shown interest in pharmacy related information. On one hand, this may be the percentage that reflects the patients with real interest in information materials. On the other hand, it may just as well be the starting point from which pharmacies can expand their information function.

Assumption 4 Consumers have potential interest for distraction. Pharmacists have to take into account that the wishes of at least some of the patients may not at all be related to pharmaceutical information, but to other forms of activities. The results show that the need for an ordinary newspaper exceeds the need of many categories, which is remarkable.
It can be expected that the behaviour of consumers in the pharmacy waiting area will reflect combinations from the above intentions. It is clear that pharmacists will have to decide how to mix activities related to information and distraction in the pharmacy waiting area. For the moment, a combination of both seems the best advice, but explicitly taking the needs and wishes of the local consumers into account. For instance, in order to select pharmaceutical information that may be relevant for the waiting area: ask the consumers what they like, make the waiting area as agreeable as possible given these functions and needs, evaluate the behaviour, and change when necessary. Consequently, the waiting area should have many different properties, fulfilling the needs of many. This approach will undoubtedly lead to different central points per pharmacy, since each pharmacy has unique properties in their patient population. Respecting their input may change the actual behaviour of consumers, and, by doing so, create new openings for the provision of information in the waiting area.

At this point we may add that transdisciplinary research has been useful in this context. The theoretical framework has crossed the borders of pharmacy practice: consumer research was used to fill the gap in pharmacy practice research. First, this approach has allowed the use of an established theoretical framework from a different but related area. Second, the chosen theoretical framework has served as a starting point for new empirical research. Third, the results can be compared with existing knowledge in both disciplines, allowing new conclusions to be drawn in pharmacy practice research. In this research differences between the disciplines seemed not to have hindered the process of data gathering or analysis, but rather provide a stimulating basis for new research in community-based pharmacy practice.

\section{Conclusion}

Based on these findings, this paper argues that few consumers obtain written information during the waiting time. Most patients only wait. The waiting area may have latent possibilities to expand the information function of the pharmacy, combine this with other activities that distract the consumer from the wait, and which also has the potential to improve customer satisfaction. New studies should concentrate on the intentions of these consumers in order to explore their needs and wishes and allow a further development in pharmaceutical care in this very specific area. Moreover, transdisciplinary research has been useful in this context. It filled the gap in pharmacy practice research with knowledge from consumer research, allowing additional information on the 
queueing behaviour of consumers. Researchers in pharmacy practice research should consider to use knowledge from different but related scientific disciplines, such as management and organization science, if the required knowledge is not available in pharmacy practice research.

Acknowledgements I thank Prof. Dr. C.J. de Blaey of the Scientific Institute for Dutch Pharmacists (WINAp), the board of the Royal Dutch Association for the Advancement of Pharmacy (KNMP), and the board of the Stichting Nicolaas Muleriusfonds for their financial support of this project. Moreover, I thank Tijs Berends, the involved pharmacy staff, and the organizations Orbit architects at Almere, Profarmaplan architects at Breda, AMP at Vught, Argo at Groningen, CLA at Drachten, Netherlands board for hospital facilities in Utrecht, $\mathrm{NP} / \mathrm{CF}$ in Utrecht, Peutz at Zoetermeer, and the unit for application development at the University of Groningen for their work and valuable support in this project.

\section{References}

1. van Mil JWF, Schulz M, Tromp ThFJ. Pharmaceutical care, European developments in concepts, implementation, teaching, and research: a review. Pharm World Sci 2004; 26:303-311
2. Hornik J. Subjective versus objective time measures: a note on the perception of time in consumer behavior. J Consum Res 1984; 11:615-618

3. Larson R. Perspectives on queues: social justice and the psychology of queueing. Oper Res 1987; 35:895-905

4. Katz K, Larson B, Larson R. Prescriptions for the waitingin-line blues: entertain, enlighten, and engage. Sloan Manage Rev 1991; 32:44-53

5. Taylor S. Waiting for service: the relationship between delays and evaluations of service. J Marketing 1994; 58:56-69

6. Bonnin G. The role of physical behaviour and spatial configuration in service encounter: two exploratory studies in a retail context. In: Eiglier P, Grönroos Ch, Rafaeli A, Rust R, (editors) 8th International Research Seminar in Servicemanagement [Proceedings]. La Londe les Maures; 2004. p. 43-64

7. Mobach MP. Functie en bezieling van bedrijfskundige kennis (Function and inspiration of managerial and organizational knowledge). In: Mobach MP and Stegwee RA, editors. Bedrijfskundige kennis: een kleurrijk spectrum (Managerial and organizational knowledge: a colourful spectrum). Groningen: Pentapark; 2004 ISBN 90-809216-1-0 